\title{
Nonrandom Chromosomal Numerical Abnormality Predicting Prognosis of Gastric Cancer: A Retrospective Study of 51 Cases Using Pathology Archives
}

\author{
Yasuhiko Kitayama, Hisaki Igarashi, Fumitoshi Watanabe, Yasuhiko Maruyama, \\ Masao Kanamori, and Haruhiko Sugimura
}

First Department of Pathology (YK, HI, HS), Department of Public Health (MK), Hamamatsu University School of Medicine, Hamamatsu, and Department of Pathology (YK), Shizuoka Saiseikai General Hospital, and Department of Pathology and Gastroenterology (YK, FW, YM), Fujieda Municipal General Hospital, Fujieda, Japan

SUMMARY: Chromosomal or centromerical numerical abnormality (CNA) is a well-known characteristic of human cancer, but the extensive and specific documentation of CNA in gastric cancer is still sparse, partly because of difficulty in obtaining cytogenetic information. Taking advantage of a recently developed fluorescence in situ hybridization protocol for formalin-fixed paraffin-embedded tissues, we investigated CNA of 51 gastric cancer cases with a panel of 18 chromosome-specific $\alpha$-satellite probes (for chromosomes 1-4, 6-12, 15-18, 20, $\mathrm{X}$ and $\mathrm{Y}$ ) and region specific probes (c-myc and p53) to enumerate respective chromosome numbers in interphase nuclei. The involved chromosomes exhibiting CNA were nonrandom in gastric cancer. Aberrations of chromosomes $1,8,17,20$, and $X$ were frequent regardless of histologic types, whereas aberrations chromosomes 10,15 , and 18 occurred less often $(p<0.001)$. From a histopathologic standpoint, the mucocellular type had stable CNA in comparison with the tubular type (mucocellular type vs tubular type carcinoma: $21.0 \pm 10.63 \%$ vs $62.8 \pm 12.79 \%, p<0.001$ ). Interestingly, there was less extensive CNA in women (men vs women: $54.3 \pm 9.49 \%$ versus $24.9 \pm 12.23 \%, p<0.001$ ). A dramatic difference in the outcome was detected according to the involvement of chromosomes 3, 10, 11, 12, 17, and Y; that is, the cases with CNA of these chromosomes had worse prognosis. (Lab Invest 2003, 83:1311-1320).

$G$ astric cancer is frequently associated with chromosomal numerical abnormality (CNA), similar to other gastrointestinal tract tumors (Lengauer et al, 1998). However, because identification of the abnormal characteristics by the conventional cytogenetic method (Abarbanel et al, 1991; Gomyo et al, 1996; Ochi et al, 1986; Seruca et al, 1993) or by flow cytometry (Kallioniemi et al, 1992) has been hampered by technical difficulties (Pinkel et al, 1986; Rao et al, 1993; van Dekken et al, 1990), minimal information has been available regarding specific chromosomal alterations in gastric cancer (Kitayama et al, 2000a; Rao et al, 1993; van Dekken et al, 1990).

We recently developed a new, sensitive, and rapid fluorescence in situ hybridization (FISH) method that

DOI: 10.1097/01.LAB.0000087622.80751.C5

Received January 24, 2003.

This work was supported by grants from the Smoking Research Foundation, the Ministry of Education, Culture, Science, Sports, Technology, and the Ministry of Health, Welfare and Work of Japan. This work was also supported by the Regional Science Promotion Program of the Japan Science and Technology Corporation and the Foundation for Promotion of Cancer Research in Japan.

Address reprint requests to: Dr. H. Sugimura, First Department of Pathology, Hamamatsu University School of Medicine, 1-20-1 Handayama, Hamamatsu 431-3192, Japan.E-mail: hsugimur@hama-med.ac.jp involves microwave (MW) pretreatment (boiling) and initial intermittent irradiation for hybridization. This new protocol is especially versatile in application for formalin-fixed paraffin-embedded tissue specimens (Kitayama et al, 1999, 2000b; Kobayashi et al, 2000; Lan et al, 1996; Sibony et al, 1995; Song et al, 2002). In this study, we applied this modified FISH technique using a panel of 18 chromosomal centromeric $\alpha$-satellite probes and two region-specific probes to a chromosome-wide search for CNA in formalin-fixed paraffin-embedded tissue specimens from 51 cases of gastric cancer. This method yielded sensitive and accurate data on the numbers of copies of respective chromosomal centromeres and specific gene loci. Thus we could compare the CNA data obtained with the several histopathologic variables in our series. The results allowed us to define different CNA profiles of respective chromosomes according to histologic subtype, stage, sex, and clinical outcome.

\section{Results}

\section{Validation of Modified FISH Method}

A distinct signal could be detected after 30 minutes of MW pretreatment and only 3 hours of in situ hybridization with 1 hour of initial intermittent MW irradiation in formalin-fixed paraffin-embedded sections of nor- 
mal gastric mucosa fixed for 1 day and cancer tissue fixed for 1 week (Fig. 1, top and bottom). We were able to obtain distinct signals and more accurate data in the 51 gastric cancer cases with all of the probes used.

We set the cutoff level for nuclei with an abnormal number of signals at $20 \%$ of all tumor nuclei. This seemed to be a safe margin, because the percentage of nuclei with an aberrant centromeric number in the control normal epithelia and lymphocytes has never exceeded $10 \%$.

\section{CNA Profiles of the Cases}

All of the histopathologic data on the 51 specimens and the distribution of tumor cells according to copy numbers of each of the 18 chromosome centromeres and two locus-specific regions (c-myc and p53) studied are summarized in Table 1. Clinical staging indicated 26 early and 25 advanced gastric cancers in this series. Chromosomal gains were detected more often than losses. In the early stage
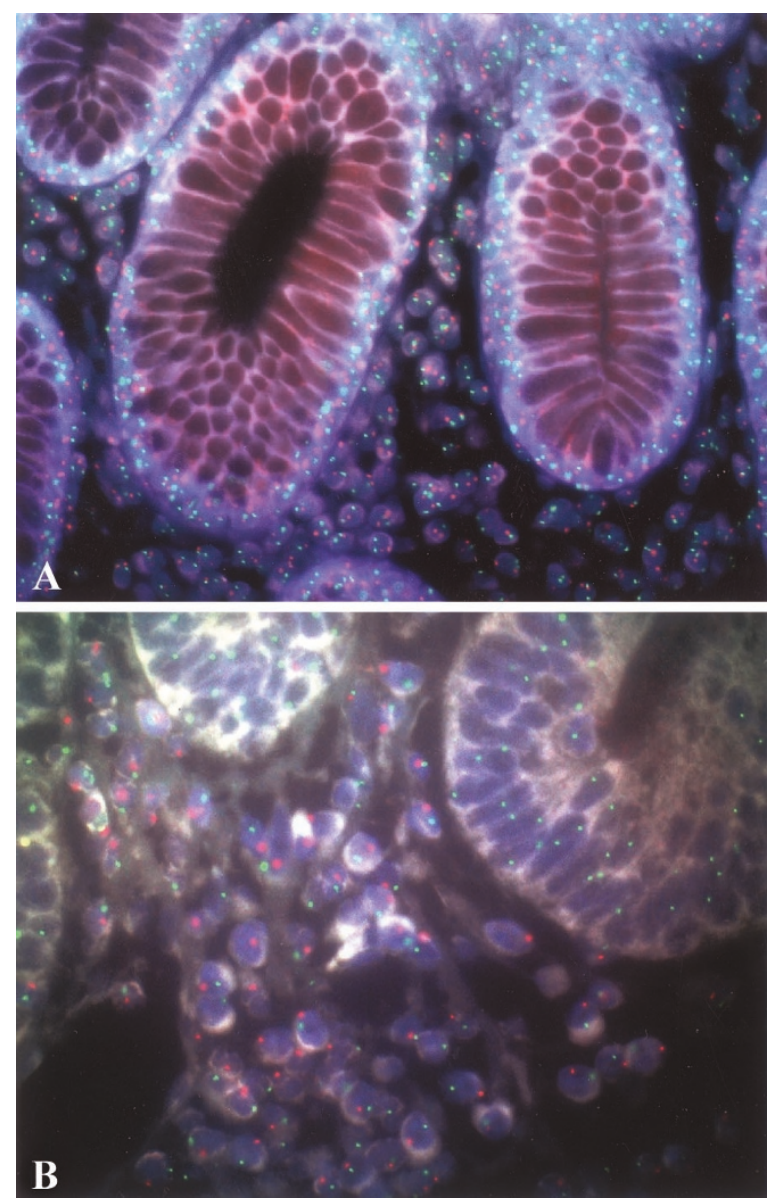

Figure 1.

Chromosome 8 centromere (green) and c-myc gene (orange) in a paraffin section of gastric mucosa fixed for 1 day. Two distinct signals were found in the epithelial and stromal cell nuclei (top). Chromosomes $X$ (green) and $Y$ (orange) in a paraffin section of gastric carcinoma fixed for 1 week. One distinct signal of an $\mathrm{X}$ and $\mathrm{Y}$ chromosome was found in normal stromal cell nuclei, whereas loss of the $Y$ was found in the nuclei of cancerous epithelium (bottom). cancers (down to the sm2 level), the most frequent abnormalities occurred in the $X$ chromosome $(61.5 \%)$, followed by chromosome $3(53.8 \%)$ and then chromosomes 17 and $Y(50 \%)$. Chromosomes 4,6 , and 15 had the lowest levels of abnormalities (19.2\%) represented by the variant fraction (VF). When the cases in all of the stages were included, chromosome $X$ most frequently had gains $(64.7 \%)$. Gains of chromosomes 1 (60.8\%), 8 (56.9\%), 20 (56.9\%), and 17 (54.9\%) followed, whereas the CNA of chromosome 18 (33.3\%) had the least gain, followed by chromosomes 10 and 15 (39.2\%) (Table 2). A graphic representation of chromosomal aberrations and their frequency as a result of histopathologic type and stage is shown in Figure 2.

Interestingly there were fewer chromosomal abnormalities in the tumors from the women in our series (Table 3). Abnormalities of chromosomes 16, 17, and 18 were rarely found in gastric cancers of the women (Table 1).

Loss of centromere or monosomy was also present in some cases. Monosomy of chromosome 1 in Case 38 and monosomy of chromosome 3 in Case 45 were noticed. Loss of the $\mathrm{Y}$ chromosome was found in 12 $(30 \%)$ of the 40 men, whereas $11(27.5 \%)$ cases showed a gain of the $\mathrm{Y}$ chromosome centromere. By contrast, although amplification of chromosome $X$ is one of the most frequent aberrations, no loss was detected in any of the samples.

\section{Histopathologic Types and CNA}

In the early stages, the well-differentiated papillary type and the mucocellular type (sig and muc-sci subtypes) of carcinoma had lower rates of chromosomal abnormalities than the tubular type (tub1, tub2, and tub-sci subtypes) (Table 1). The total prevalence of the CNA, except for chromosomes 3 and $Y$, was greater in the tubular type (pap, tub1, and tub2) of carcinoma than in the mucocellular type $(62.82 \%$ vs $21.0 \% ; p<0.001$ ) (Table 3). Most mucocellular cases showed few abnormalities in the numbers of chromosome centromeres in the early stages (depth $\mathrm{m}$ and sm1 levels). When the cancer invaded the lower submucosal layer (sm2) and proper muscle layer, additional and more extensive abnormalities in centromere copy numbers were found. However, no abnormal changes in any of the chromosomes tested were found in three early cases or even in one advanced case (Case 50) of the mucocellular type. By contrast, the tubular type of carcinoma had a higher rate of abnormalities even in the early stages, and further chromosome abnormalities were added as the cancer progressed (Table 1).

\section{Other Clinicopathologic Variables and CNA}

CNA of the younger patients ( $<60$ years old) were infrequent compared with that of older patients in general, because in the younger patients, the mucocellular type occurs more often than the tubular type of gastric carcinoma. The cases with severe intestinal 
Table 1. Clinicopathological Features and Genomic Alterations in 51 Gastric Cancers

\begin{tabular}{|c|c|c|c|c|c|c|c|c|c|c|}
\hline \multirow[b]{2}{*}{ Case } & \multirow{2}{*}{$\begin{array}{l}\text { Sex/ } \\
\text { age }\end{array}$} & \multirow[b]{2}{*}{ Pathology } & \multirow[b]{2}{*}{ Depth } & \multirow[b]{2}{*}{ Stage } & \multicolumn{2}{|l|}{ Chromosome centromeric aberrations by FISH } & \multirow{2}{*}{$\begin{array}{c}\text { Average } \\
\text { of MN }\end{array}$} & \multirow{2}{*}{$\begin{array}{l}\text { c-myc } \\
\text { (FISH) }\end{array}$} & \multirow{2}{*}{$\begin{array}{c}\text { p53 } \\
\text { (FISH) }\end{array}$} & \multirow{2}{*}{$\begin{array}{c}\text { HER-2/ } \\
\text { neu } \\
(\mathrm{IHC})\end{array}$} \\
\hline & & & & & Gain & Loss & & & & \\
\hline 1 & $M / 68$ & pap & $\mathrm{m}$ & la & $2,16, x$ & & 2.1 & $\mathrm{~N}$ & $\mathrm{~N}$ & - \\
\hline 2 & $\mathrm{M} / 51$ & pap & $\mathrm{m}$ & la & $3,4,16,17$ & & 2.1 & $\mathrm{~N}$ & N & - \\
\hline 3 & $\mathrm{M} / 71$ & pap & $\mathrm{m}$ & la & $3,17, x$ & & 2.2 & $\mathrm{~N}$ & Loss & + \\
\hline 4 & M/66 & pap & $\mathrm{m}$ & la & $3,12,17, X, Y$ & & 2.1 & N & N & - \\
\hline 5 & M/66 & pap & sm1 & la & $3,4,11,12$ & Y & 1.94 & N & N & - \\
\hline 6 & $\mathrm{M} / 75$ & pap & sm1 & la & 1 & & 2.1 & N & N & + \\
\hline 7 & $\mathrm{M} / 79$ & pap & se & IIIb & $1,4,6,7,8,12, x$ & & 2.35 & N & Loss & + \\
\hline 8 & $\mathrm{M} / 72$ & tub1 & $\mathrm{m}$ & la & $1,3,6,7,10,16,17,18,20, X$ & Y & 2.24 & N & N & - \\
\hline 9 & $\mathrm{M} / 60$ & tub1 & $\mathrm{m}$ & la & $1,3,4,6,8,9,10,11,16,17,18,20, x$ & Y & 2.47 & N & Loss & - \\
\hline 10 & M/63 & tub1 & $\mathrm{m}$ & la & $1,2,3,7,11,15,16,17,20, X, Y$ & & 2.35 & N & Loss & - \\
\hline 11 & $\mathrm{~F} / 72$ & tub1 & $\mathrm{m}$ & la & $1,2,3,6,7,8,9,10,11,12,17,20$ & - & 2.35 & N & Loss & + \\
\hline 12 & $M / 62$ & tub1 & sm2 & Ib & $1,6,7,8,10,11,12,16,17,20, x$ & & 2.65 & Gain & N & + \\
\hline 13 & $\mathrm{M} / 72$ & tub1 & sm2 & la & $1,2,3,4,6,7,8,9,11,12,15,16,17,18,20, X, Y$ & & 2.88 & $\mathrm{~N}$ & Loss & - \\
\hline 14 & $\mathrm{~F} / 84$ & tub1 & $\mathrm{mp}$ & Ib & $1,2,8$ & - & 2.12 & Gain & $\mathrm{N}$ & - \\
\hline 15 & $\mathrm{M} / 71$ & tub1 & $\mathrm{mp}$ & Ib & $1,3,4,6,7,8,9,10,11,12,15,16,18,20, X$ & & 3.06 & $\mathrm{~N}$ & N & - \\
\hline 16 & $\mathrm{M} / 76$ & tub1 & SS & Ib & $1,2,3,4,6,7,8,9,10,11,12,15,16,17,18,20, X, Y$ & & 3.24 & $\mathrm{~N}$ & N & - \\
\hline 17 & M/62 & tub1 & ss & Iva & $1,2,4,6,8,9,12,15,16,17,18,20, X, Y$ & & 2.71 & $\mathrm{~N}$ & N & + \\
\hline 18 & $\mathrm{M} / 45$ & tub1 & se & IIIb & $1,2,20$ & & 2.1 & $\mathrm{~N}$ & N & - \\
\hline 19 & $\mathrm{~F} / 80$ & tub1 & se & IIIb & $2,3,4,6,8,9,10,11,12,15,17,18,20, X$ & - & 2.88 & $\mathrm{~N}$ & N & + \\
\hline 20 & $\mathrm{M} / 73$ & tub1 & se & IVa & $1,4,6,7,8,11,12,15,18,20, X, Y$ & & 2.41 & N & N & + \\
\hline 21 & $M / 87$ & tub2 & sm2 & la & $1,2,3,7,8,9,10,11,12,15,16,17,18,20, x$ & Y & 3 & N & N & - \\
\hline 22 & $\mathrm{M} / 54$ & tub2 & sm2 & lb & $1,2,7,8,9,10,11,12,15,16,17,18,20, x$ & & 2.88 & N & N & - \\
\hline 23 & M/68 & tub2 & $\mathrm{mp}$ & Ib & $1,2,3,4,6,7,8,9,10,11,12,15,16,17,18,20, X$ & Y & 3.41 & Gain & N & - \\
\hline 24 & $\mathrm{~F} / 85$ & tub2 & $\mathrm{mp}$ & II & $1,2,4,8,15,20$ & - & 2.29 & Gain & N & - \\
\hline 25 & $\mathrm{M} / 59$ & tub2 & SS & II & $1,2,4,6,7,8,9,15,16,17, x$ & & 2.71 & $\mathrm{~N}$ & N & + \\
\hline 26 & $\mathrm{M} / 74$ & tub2 & SS & IIla & $1,2,4,6,7,8,9,10,11,12,15,16,17,18,20$ & Y & 2.76 & Gain & $\mathrm{N}$ & - \\
\hline 27 & $\mathrm{M} / 56$ & tub2 & SS & Ivb & $1,3,4,6,7,8,9,10,11,12,15,16,17,18,20, X, Y$ & & 3.24 & $\mathrm{~N}$ & Loss & - \\
\hline 28 & $\mathrm{M} / 79$ & tub2 & se & IIla & $1,2,4,6,7,8,9,10,11,12,15,16,17,18,20, x$ & Y & 2.88 & N & $\mathrm{N}$ & - \\
\hline 29 & $\mathrm{M} / 67$ & tub2 & se & IIIb & $4,8,20, x$ & & 2.24 & Gain & $\mathrm{N}$ & - \\
\hline 30 & $\mathrm{M} / 43$ & tub2 & se & $\mathrm{IVb}$ & $1,2,3,4,6,7,8,9,10,11,12,15,16,17,18,20, x$ & Y & 3.41 & Gain & $\mathrm{N}$ & - \\
\hline 31 & $\mathrm{M} / 71$ & tub-sci & ss & $\mathrm{lb}$ & $1,2,3,4,6,7,8,9,10,11,12,16,17,20, X, Y$ & & 3.18 & Gain & $\mathrm{N}$ & + \\
\hline 32 & M/66 & tub-sci & se & IIla & $1,2,3,4,6,7,8,9,10,12,15,16,17,20, X, Y$ & & 3.18 & $\mathrm{~N}$ & Loss & + \\
\hline 33 & $\mathrm{M} / 82$ & tub-sci & se & IIla & $1,3,4,6,7,8,9,10,12,17, X, Y$ & & 2.71 & N & $\mathrm{N}$ & - \\
\hline 34 & $\mathrm{M} / 64$ & tub-sci & se & IVb & $1,2,3,4,6,7,8,9,10,11,12,16,17,18,20$ & Y & 2.94 & Gain & $\mathrm{N}$ & - \\
\hline 35 & $\mathrm{~F} / 67$ & $\operatorname{sig}$ & $\mathrm{m}$ & la & & - & 2 & $\mathrm{~N}$ & $\mathrm{~N}$ & - \\
\hline 36 & $\mathrm{~F} / 58$ & sig & $\mathrm{m}$ & la & & - & 2 & $\mathrm{~N}$ & $\mathrm{~N}$ & + \\
\hline 37 & $\mathrm{M} / 64$ & sig & $\mathrm{m}$ & la & $X, Y$ & & 2.1 & $\mathrm{~N}$ & Loss & - \\
\hline 38 & $\mathrm{M} / 68$ & sig & $\mathrm{m}$ & la & $17, x$ & $3, Y$ & 1.94 & $\mathrm{~N}$ & $\mathrm{~N}$ & - \\
\hline 39 & $\mathrm{~F} / 32$ & sig & $\mathrm{m}$ & la & 3 & - & 2 & $\mathrm{~N}$ & $\mathrm{~N}$ & + \\
\hline 40 & $\mathrm{~F} / 53$ & sig & sm1 & la & & & 2 & $\mathrm{~N}$ & $\mathrm{~N}$ & - \\
\hline 41 & $\mathrm{M} / 52$ & sig & sm1 & la & & & 2 & $\mathrm{~N}$ & $\mathrm{~N}$ & - \\
\hline 42 & $\mathrm{M} / 66$ & sig & sm1 & la & $8, X$ & $Y$ & 2.1 & $\mathrm{~N}$ & $\mathrm{~N}$ & - \\
\hline 43 & $\mathrm{M} / 37$ & sig & sm1 & $\mathrm{Ib}$ & 20 & & 2 & $\mathrm{~N}$ & $\mathrm{~N}$ & - \\
\hline 44 & $\mathrm{~F} / 49$ & sig & sm2 & la & 3 & - & 2 & $\mathrm{~N}$ & $\mathrm{~N}$ & - \\
\hline 45 & $\mathrm{M} / 51$ & sig & sm2 & $\mathrm{Ib}$ & $X$ & 1 & 1.94 & $\mathrm{~N}$ & $\mathrm{~N}$ & - \\
\hline 46 & $\mathrm{M} / 69$ & sig & sm2 & la & $2,3,4,8,9,10,11,12,15,17,18,20, X$ & $\mathrm{Y}$ & 2.47 & Gain & $\mathrm{N}$ & - \\
\hline 47 & $\mathrm{M} / 50$ & sig & $\mathrm{mp}$ & $\mathrm{Ib}$ & $1,2,4,7,8,9,15,16,17,20, x$ & & 2.53 & Gain & $\mathrm{N}$ & - \\
\hline 48 & $\mathrm{M} / 75$ & muc-sci & se & IIIb & $4,6,7$ & & 2.1 & N & Loss & - \\
\hline 49 & $\mathrm{M} / 43$ & muc-sci & se & IVb & $1,2,4,16,20$ & & 2.18 & $\mathrm{~N}$ & $\mathrm{~N}$ & - \\
\hline 50 & $\mathrm{~F} / 43$ & muc-sci & si & IVb & & & 2 & $\mathrm{~N}$ & $\mathrm{~N}$ & - \\
\hline 51 & $\mathrm{~F} / 46$ & muc-sci & si & $\mathrm{IVb}$ & $1,2,3,4,6,7,8,9,10,11,12,15,17,20, X$ & - & 2.71 & Gain & $\mathrm{N}$ & - \\
\hline & Control & LN & & & & & 2 & $\mathrm{~N}$ & $\mathrm{~N}$ & - \\
\hline
\end{tabular}

N, ๑०. Clinicopathological variables and genomic alterations of the 51 gastric cancer cases. For each chromosomal centromere and locus-specific gene tested, abnormal amplifications and losses were evaluated by FISH analysis. Normal lymphocyte (Control LN) were used as a control shown in the lower column. HER-2/neu expression was determined by immunohistochemistry.

metaplasia in the background mucosa and those with positive Helicobacter pylori infection were both affected with extensive CNA (Table 3). The relationships of c-myc, P53, and HER-2/neu gene amplifications and clinicopathologic features were not remarkable except for stage (Table 3). 
Table 2. Frequency of Abnormal Cells with a Chromosome Number of $\geqq 3$ or $\leqq 1$

\begin{tabular}{lccc}
\hline & Frequent chromosomes & Infrequent chromosomes & Statistical analysis \\
\hline Stage & $1,8,17,20, \mathrm{X}$ & $10,15,18$ & \\
Early $(\mathrm{m}$ to sm) & $60 / 124(48.4 \%)$ & $18 / 78(23.1 \%)$ & $p<0.001$ \\
Advanced (mp to si) & $93 / 120(77.5 \%)$ & $37 / 75(49.3 \%)$ & $p<0.005$ \\
& $p<0.001$ & $p<0.001$ & \\
Total & $153 / 244(62.7 \%)$ & $55 / 153(35.9 \%)$ & $p<0.001$ \\
\hline
\end{tabular}

\section{Clinical Outcome and CNA Profile}

In general, both the prevalence and the numbers of numerical chromosomal centromeric abnormalities increased with clinical stage (Table 1). Stage Illa specimens exhibited the highest abnormality rate $(86.1 \%)$ overall, and stage la specimens had the lowest rate (32.3\%). We had only five cases with distant metastasis $(19,20,27,30$, and 51$)$ in our series, and severe CNA were observed in the primary tumors in all of them (Table 1).

On the other hand, seven advanced cases $(14,18$, $24,29,48,49$, and 50) had fewer chromosomal aberrations, and the follow-up of these cases showed they all survived for 5 years or more after surgery (Tables 1 and 4). For example, in Case 50, a patient with Borrmann type IV advanced cancer and multiple lymph node metastases at the operation has survived for 11 years without recurrence after gastrectomy, and retrospective investigation of the original cancer tissue for CNA revealed hardly any abnormalities. By contrast, in Case 51, the patient had a Ilc type early gastric cancer with lymph node metastasis and died of carcinomatous meningitis, pleuritis, and peritonitis 6 months later. The investigation of CNA in the original cancer in this case revealed extensive aberrations in many chromosomes. Although the morphologic features appeared similar in hematoxylin and eosinstained sections, our FISH procedure revealed very different frequencies of chromosomal alterations and they reflected the outcome.

From a standpoint of the comparison of CNA and the outcome of 25 advanced cancer cases, we found that CNA of particular sets of chromosomes (chromosomes $3,10,11,12,17$, and $Y$ ) strongly reflected the difference in outcome. Although this selection of the combination of the chromosomes was based on careful inspection, they significantly predicted prognosis in our analysis. That is, CNA of these six chromosomes and locus-specific gene amplifications (Table 4, Fig. 3) were detected in the cases with poorer prognosis. On the other hand, in long-surviving cases (such as Cases $15,26,28$, and 33), these chromosomes were not

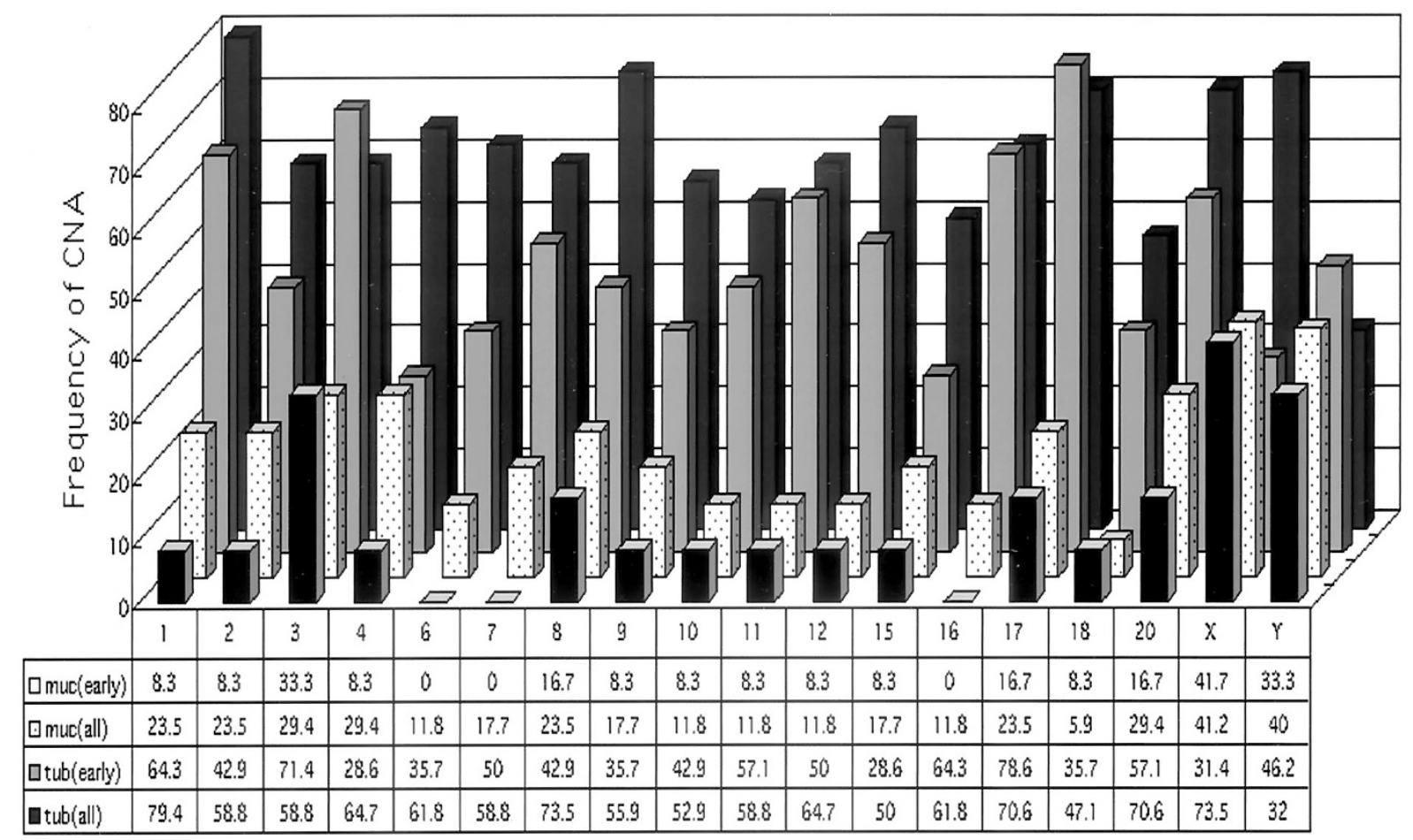

\section{Figure 2.}

The frequency of numerical centromeric alterations of each chromosome and the pathologic subtypes of the 51 gastric cancers. Fluorescence in situ hybridization (FISH) analysis of 18 centromere probes and comparison of the frequency of numerical abnormalities between the tubular (tub) and mucocellular type (muc) in each stage of carcinoma. 


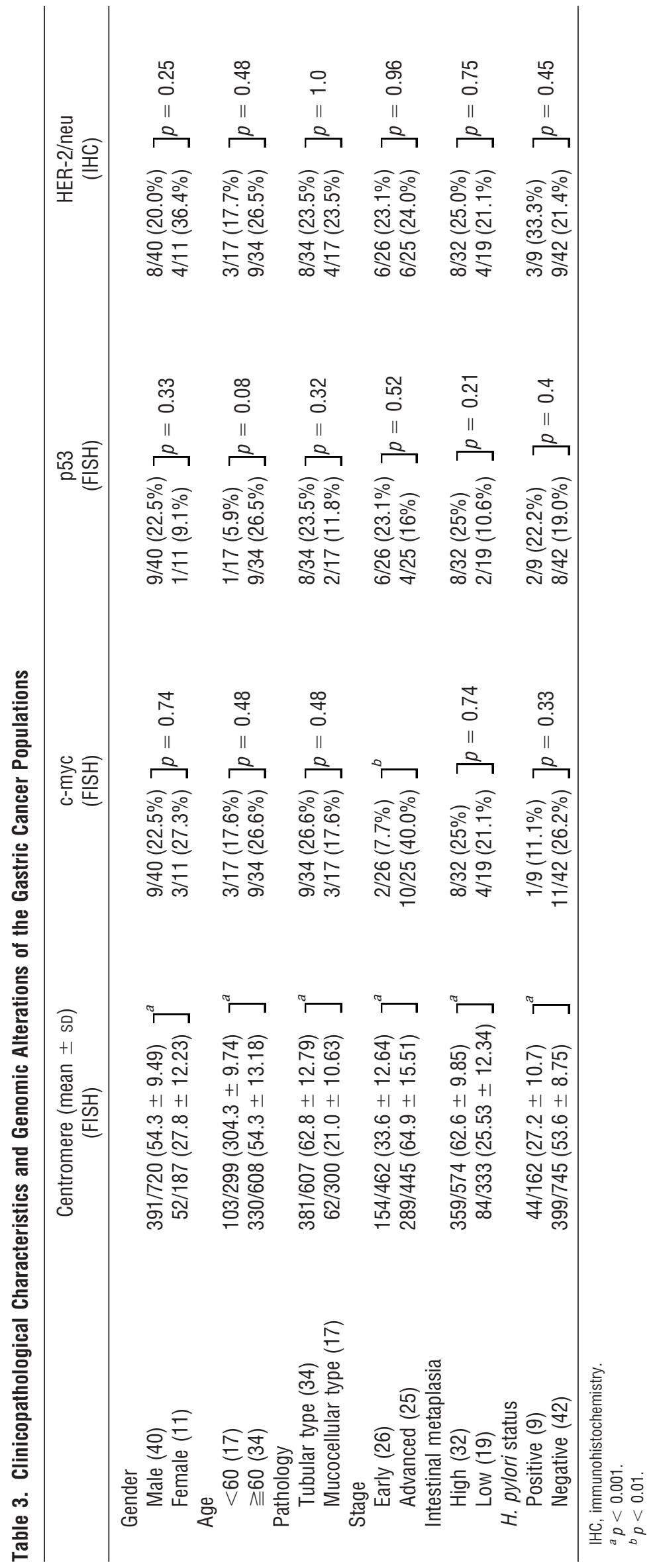


Table 4. CNA of Chromosomes 3, 10, 11, 12, 17, Y, Genomic Alterations, and Survival in 24 Advanced Gastric Cancers

\begin{tabular}{|c|c|c|c|c|c|c|}
\hline No. of cases & Abnormal chromosomes & c-myc & p53 & HER-2/neu & Survival time & \\
\hline \multicolumn{7}{|l|}{ CNA high } \\
\hline Case 15 & $3,10,11,12$ & $\mathrm{~N}$ & $\mathrm{~N}$ & - & $5 Y 5 M$ & Alive \\
\hline Case 17 & $12,17, \mathrm{Y}$ & $\mathrm{N}$ & $\mathrm{N}$ & + & $1 Y 8 M$ & Death \\
\hline Case 19 & $3,10,11,12,17$ & $\mathrm{~N}$ & $\mathrm{~N}$ & + & $8 \mathrm{M}$ & Death \\
\hline Case 20 & $11,12, Y$ & $\mathrm{~N}$ & $\mathrm{~N}$ & + & $7 \mathrm{M}$ & Death \\
\hline Case 23 & $3,10,11,12,17, Y$ & Gain & $\mathrm{N}$ & - & $1 Y 7 M$ & Death \\
\hline Case 26 & $10,11,12,17, \mathrm{Y}$ & $\mathrm{N}$ & $\mathrm{N}$ & - & $5 Y 4 M$ & Alive \\
\hline Case 27 & $3,10,11,12,17, Y$ & $\mathrm{~N}$ & Loss & - & $4 \mathrm{M}$ & Death \\
\hline Case 28 & $10,11,12,17, \mathrm{Y}$ & $\mathrm{N}$ & $\mathrm{N}$ & - & $3 Y 7 \mathrm{M}$ & Death \\
\hline Case 30 & $3,10,11,12,17, Y$ & Gain & $\mathrm{N}$ & - & $3 \mathrm{M}$ & Death \\
\hline Case 31 & $3,10,11,12,17, Y$ & Gain & $\mathrm{N}$ & + & $2 Y$ & Death \\
\hline Case 32 & $3,10,11,12,17, Y$ & $\mathrm{~N}$ & Loss & + & $2 Y 10 M$ & Death \\
\hline Case 33 & $3,10,12,17, Y$ & $\mathrm{~N}$ & $\mathrm{~N}$ & - & $4 Y 10 M$ & Death \\
\hline Case 34 & $3,10,11,12,17, Y$ & Gain & $\mathrm{N}$ & - & $1 Y$ & Death \\
\hline Case 51 & $3,10,11,12,17$ & Gain & $\mathrm{N}$ & - & $6 \mathrm{M}$ & Death \\
\hline \multicolumn{7}{|l|}{ CNA low } \\
\hline Case 7 & 12 & $\mathrm{~N}$ & Loss & + & $1 Y 10 M$ & Death \\
\hline Case 14 & - & Gain & $\mathrm{N}$ & - & $7 Y 3 M$ & Alive \\
\hline Case 18 & - & $\mathrm{N}$ & $\mathrm{N}$ & - & $5 Y 9 M$ & Alive \\
\hline Case 24 & - & Gain & $\mathrm{N}$ & - & $5 Y 2 M$ & Alive \\
\hline Case 25 & 17 & $\mathrm{~N}$ & $\mathrm{~N}$ & - & $5 Y 1 M$ & Alive \\
\hline Case 29 & - & Gain & $\mathrm{N}$ & - & $5 Y 3 M$ & Alive \\
\hline Case 47 & 17 & Gain & $\mathrm{N}$ & - & $5 Y 2 M$ & Alive \\
\hline Case 48 & - & $\mathrm{N}$ & Loss & - & $7 \mathrm{YYM}$ & Alive \\
\hline Case 49 & - & $\mathrm{N}$ & $N$ & - & $7 \mathrm{Y} 8 \mathrm{M}$ & Alive \\
\hline Case 50 & - & $\mathrm{N}$ & $\mathrm{N}$ & - & $11 Y 6 M$ & Death \\
\hline
\end{tabular}

N, ๑०; Y, years; M, months.

changed. The survival analysis including 25 advanced gastric cancer cases (Kaplan-Meier analysis) clearly verified the predictive value of these chromosomal changes for the outcome (Fig. 3).

Case 7, with short-term survival despite less extensive CAN, was exceptional because there was a loss of the P53 gene and remarkable amplification of the HER-2/neu gene (Table 4). On the basis of these results, we attempted to devise a practical flow chart for prediction of clinical outcome of advanced gastric cancer according to the profile of CNA and locusspecific gene amplification in gastric cancer at the operation.

\section{Discussion}

We previously documented numerical abnormalities in fresh touch specimens from 24 cases of gastric cancer and suggested a sequential process of increasing chromosomal numerical abnormalities during gastric cancer progression (Kitayama et al, 2000a). We recently modified the FISH technique to facilitate retrospective study of pathology archives, and in this study we applied it to 51 specimens of gastric cancer in the pathology archives and retrospectively assessed their CNA and the biologic features. This is the first extensive study of CNA of respective chromosomes in gastric cancer pathology archives. The results provide more detailed and specific information about CNA in gastric cancer than those obtained by DNA ploidy and other methodology. We believe that the methodology we adopted in the interphase cytogenetic study of formalin-fixed paraffin-embedded tissue sections successfully paved the way for the wider use of pathologic archives for the research of cancer genome anatomy (Simpson et al, 1996; van Dekken et al, 1990). Another advantage of this method is that it could make it possible to handle smaller lesions not easily separated from the surrounding benign or premalignant cells. Our series included considerable portions of early stage cases; thus the information obtained here may be of greater etiologic importance than information obtained by CGH, sky, and other molecular analyses that use advanced cancer tissues.

Our initial analysis also showed nonrandom changes in CNA, that is, more frequent involvement of chromosomes 1, 2, 4, 8, and 20 and much less of chromosomes 3 and 18 (Kobayashi et al, 2000). In this report, we extended the study to every histologic subtype of gastric cancer stored in the pathology department for the last 20 years and confirmed our previous findings in part: the vulnerability of the chromosomes was nonrandom. In particular our extensive retrospective search also found chromosomes 1 and 20 were the most frequently affected autosomal chromosomes, and chromosome 18 was the most protected chromosome. In our series, changes in chromosome 3 were found to be frequent in the early stage of a particular subtype, "pap," which had not been 


\section{Survival Curve}

(Kaplan-Meier,Survival Analysis for TIME)

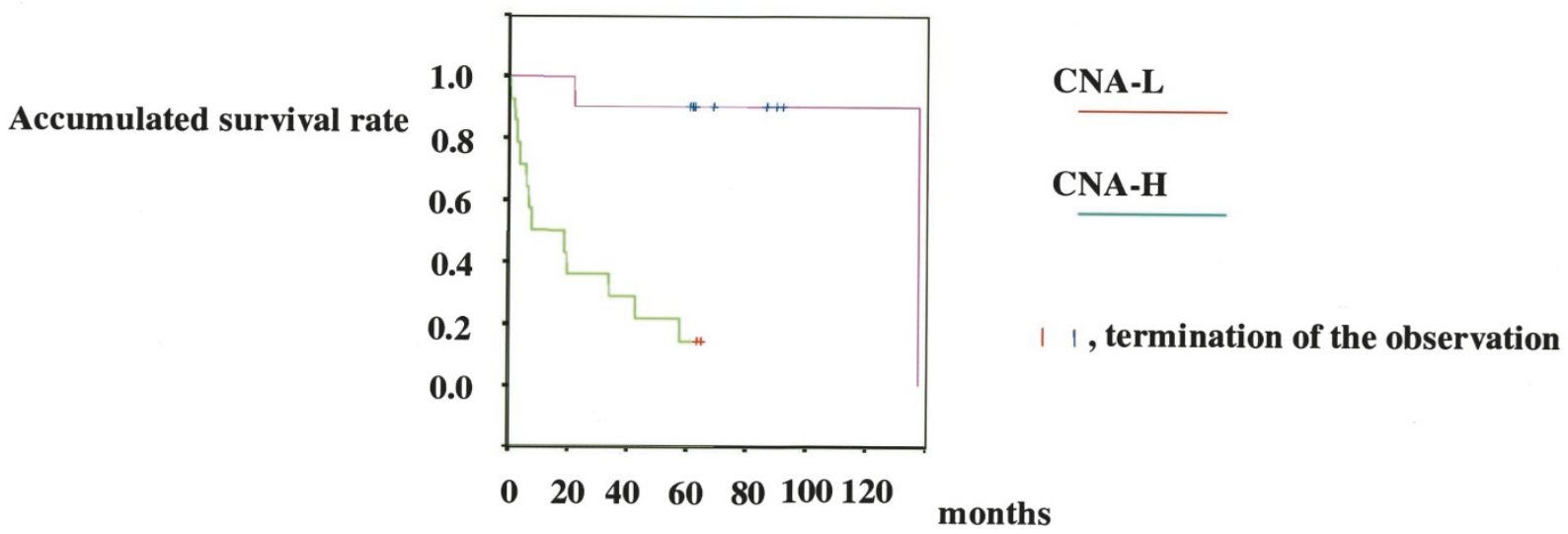

Figure 3.

Kaplan-Meier survival curve in 24 advanced gastric cancer cases according to the involvement of chromosomes 3, 10, 11, 12, 17, and Y. Significant differences in long-term survival were observed between two groups, the cases with alterations of these chromosomes $(n=14)$ and those without $(n=10)$. Survival probability was $90 \%$ in the latter group and $15 \%$ in the former group. The survival probability differs significantly between the two groups $(p<0.0001)$. $n=$ the number of patients in each group.

included in the first study set (Kitayama et al, 2000a); this was also consistent with our single case report (Kobayashi et al, 2000). In our series, CNA in the deeper layer of the gastric wall of invasion was more extensive than that in the superficial layer. The biologic behavior of gastric cancer cells may be different depending on where they located in the gastric wall. This is also further evidence for our previous assertion of stepwise changes according to the stage of gastric cancer.

The different outcomes of the advanced cancer in the same stage according to the CNA were remarkable. Survival analysis including 25 advanced gastric cancer cases (Kaplan-Meier analysis) clearly verified the predictive value of these chromosomal changes for the outcome (Fig. 3). We selected the most predictive chromosomes to obtain useful information by the minimal efforts of the FISH procedure based on the data in this study. As shown in the flow chart in Figure 4, two-step analysis of CNA and locus-specific gene amplification efficiently divided the cases of gastric cancer into those with good outcome and those with poor outcome. This analysis predicts more than a simple classification based on histopathologic types and clinical stages.

Although the responsible genes in this set of chromosomes for poorer prognosis are unknown and there are no known reasons why these chromosomes are deterministic, we are now continuously recruiting cases and refining the algorithm. Multivariate analysis would help to identify the combination of chromosome abnormalities that might improve our ability to predict prognosis in the future.

Several reports have mentioned sex chromosome abnormalities in gastric cancer (Ochi et al, 1986; Rao et al, 1993; van Dekken et al, 1990). Actually, sex chromosomes change was an frequent finding in our study. X chromosomal centromeric gain was fre- quently detected in our series, and no $X$ loss was detected. By contrast, gains and losses of chromosome $Y$ occurred with equal frequency $(27.5 \%$ vs $30 \%)$ in our study. There were fewer abnormalities in the chromosomal centromeres of tumors from women, and no abnormalities were found in chromosome 16 in any of the 11 women. We cannot explain the reason for this observation.

Various genes and loci have been reported altered in gastric cancer. They include amplifications of c-met on chromosome 7p (Kuniyasu et al, 1992), c-myc on $8 \mathrm{q}$, K-sam on $12 \mathrm{q}$, the E-cadherin gene on $17 \mathrm{p}$ (Guilford et al, 1999) and c-erbB2 on 17q (David et al, 1992; Tsugawa et al, 1993), and somatic mutations of

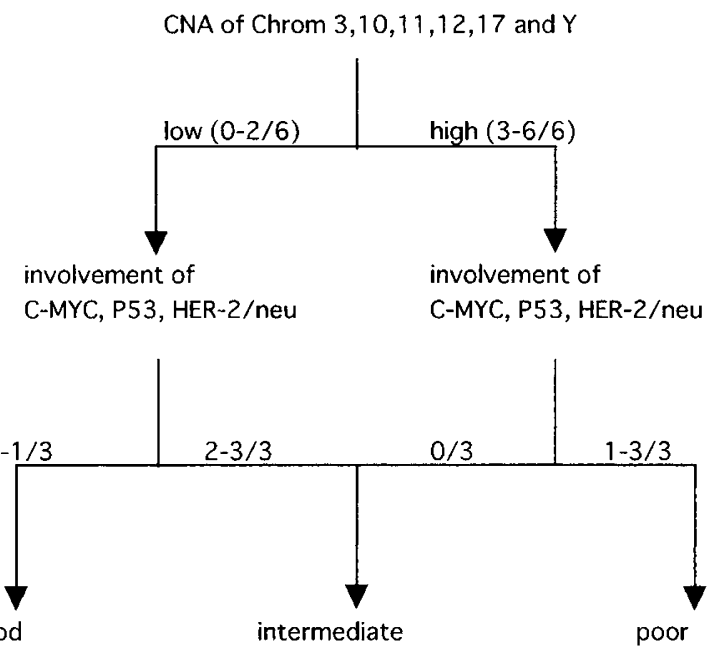

Figure 4.

A flow chart of the two-step analysis for predicting the outcome of advanced gastric cancer. We propose this algorithm, the most practical at this moment, which uses selective chromosomes and locus-specific genes. Tests for the six chromosome centromeres 3,10,11, 12, 17, and $Y$ and three loci, c-myc, P53 and HER-2/neu, are included. 
APC on $5 q$ (Nakatsuru et al, 1993), K-ras-2 on 12 q (Ranzani et al, 1993), and p53 gene on 17p (Kim et al, 1991; Matozaki et al, 1992; Renault et al, 1993). Because our FISH analysis did not include these specific loci, the integration of these data and ours is a challenge for the future.

It would also be intriguing to investigate the mechanistic basis for the CNA. Lengauer et al $(1997,1998)$ have proposed genes involved in the cell cycle check point may play a role in generating chromosomal instability. They further claimed chromosomal instability and microsatellite instability are two distinct (mutually exclusive) pathways of carcinogenesis. We have already reported that a particular subset of gastric cancer with frequent MIN has less CAN; this may be the case with gastric cancer also. Further investigation in this line is needed.

The observation of nonrandomness documented here in gastric cancer can be extended to other solid tumors. In the future, FISH studies of archival material with probes covering the whole genome will provide much essential information in regard to genetic changes that is complementary to integrative studies of human solid tumors, such as chip technology (Schraml et al, 1999).

\section{Materials and Methods}

\section{Samples}

All samples were obtained from surgically resected specimens in the pathology archives of Hamamatsu University Hospital and affiliated hospitals. The specimens consisted of 51 gastric cancers from 40 men and 11 women, whose median age at the time of surgery was 63.7 (range, 32-87) years. The tissue samples had been fixed in a $4 \%$ neutral buffered formaldehyde for 1 to 7 days at room temperature, processed with paraffin wax in the routine manner, and stored for up to 12 years at room temperature. A 6- to 8- $\mu \mathrm{m}$ section of each specimen that included the tumor and adjacent mucosa was used for histologic classification and modified FISH analysis.

\section{Histologic Evaluation}

Adjacent sections were routinely stained with hematoxylin and eosin. The tumors were histologically classified according to the Japanese Classification System (Nishi et al, 1995). Representative pictures of each histologic type are also available in this book. Differentiated (intestinal) carcinomas were further subclassified into papillary (pap) and well-differentiated (tub 1) or moderately differentiated (tub 2) types according to the degree of gland formation (Schlemper et al, 2000). Poorly differentiated (diffuse) carcinomas were also further subclassified into solid type (por 1) and nonsolid type (por 2) according to tumor cell adhesiveness. The latter category was subclassified into tubular type with scirrhous infiltration (tub-sci), mucocellular type with scirrhous infiltration (muc-sci), and signet-ring cell carcinoma (sig). The invasiveness of the tumor in the submucosal layer of the gastric wall was graded as sm1 (invasion of the upper half of the submucosal connective tissue layer) or sm2 (invasion of the deep half of the submucosal layer). Details of these descriptions about the definitions have been provided elsewhere (Nishi et al, 1995).

\section{Modified FISH}

Formalin-fixed paraffin-embedded tissue sections (6-8 $\mu \mathrm{m}$ thick) of noncancerous gastric mucosa, carcinomas, and normal lymph nodes were analyzed by the modified FISH technique. A panel of 18 centromeric $\alpha$-satellite DNA probes (chromosomes 1-4, $6-12,15-18,20, X$, and $Y$ ) and two region-specific probes (c-myc and P53) were purchased from Vysis Inc. (Downers Grove, Illinois). All probes had been labeled with either orange (Cy3) or green (FITC) using digoxigenin-11-dUTP and nick translation (Lichter et al, 1991). The sections were dewaxed by five successive 3-minute washes in xylene, followed by five washes in ethanol and MW heating for 10 minutes in a $0.01 \mathrm{M}$ citrate buffer ( $\mathrm{pH}$ 6.0). After exposure to $0.2 \%$ pepsin/0.01 N HCL for 10 minutes at $37^{\circ} \mathrm{C}$, the samples were aged in $0.1 \% \mathrm{NP}-40 / 2 \times$ SSC for 10 minutes at $37^{\circ} \mathrm{C}$ and their DNA was denatured in $70 \%$ formamide $/ 2 \times$ SCC for 5 minutes at $85^{\circ} \mathrm{C}$. A $10-\mu l$ sample of the probe solution (hybridization buffer $7 \mu$, probe $1 \mu \mathrm{l}$, DW $2 \mu \mathrm{l}$ ) was then placed on a glass slide with a coverslip, and the sample slides with the hybridization mixture were placed in a MW processor (MI-77; Azumaya Company, Tokyo, Japan). The samples were intermittently irradiated $(2.45 \mathrm{GHz}, 300 \mathrm{~W}), 3$ seconds on and 2 seconds off, with a temperature sensor set at $42^{\circ} \mathrm{C}$, as described previously. Each specimen was subjected to intermittent MW irradiation during the first hour of in situ hybridization (6 hours). DAPI I (4,6-diamidine-2-phenylindol, $125 \mathrm{ng} /$ $\mathrm{ml}$; Vysis Inc.) was used for nuclear counterstaining.

\section{Indices and Evaluation}

The slides were promptly examined under a fluorescence microscope equipped with epifluorescence filters and a photometric CCD camera (Quantix 1400; Roper Scientific, Tucson, Arizona). The images captured were digitized and stored in the image analysis program (I.P. Lab, Scanalytics, Fairfax, Virginia). In each case, two pathologists took a picture and counted the signals independently and the mean value was taken.

We used two indices, modal number and VF, to evaluate the numerical abnormalities of the 18 chromosomal centromeres and two locus-specific loci in 100 or more tumor cell nuclei of the cancer in every case with submucosal and deeper invasion. We defined the modal centromeric number $(\mathrm{MN})$ as the most prevalent number of the corresponding chromosomal centromere in the tumor cells. VF was defined as the percentage of tumor cells whose centromeric copy number differed from the mode. The average of individual chromosomes was considered the ploidy level of the tumor. Thus, lesions with chromosomal (centro- 
meric) numerical aberrations (CNA) are defined based on these two indices.

\section{Statistical Analysis}

All computation in this study was performed with the Statistical Analysis System (SAS version 8.1; SAS Inc., Cary, North Carolina). Differences in the categorical variables of the characteristics, for examples, differences between the frequency of CNA and histologic types, depth or stage categories, were compared using a $\chi^{2}$ test. The survival data analysis of the Kaplan-Meier method was performed to clear the effects of these chromosomal changes on prognosis of subjects with advanced gastric cancer. Statistical differences in two subgroups were compared using a log-rank test. A $p$ value $<0.05$ was considered statistically significant (Mori et al, 1992).

\section{Immunohistochemistry for HER-2/neu}

Formalin-fixed, paraffin-embedded tissue was cut into 3- $\mu \mathrm{m}$-thick sections. The tissues were dewaxed with xylene three times and rehydrated. To unmask the HER-2/neu antigen, the slides were boiled for 15 minutes in $0.1 \%$ citrate buffer. Endogenous peroxidase activity was blocked with $100 \%$ methanol containing 1\% hydrogen peroxide. mAb HER-2/neu (Ventana, Tokyo, Japan) was applied to the sections at a dilution of $1: 50$ and incubated at $4^{\circ} \mathrm{C}$ overnight. Antibody binding was detected by means of the streptavidin-biotin complex system (Nichirei, Tokyo, Japan), and the sections were counterstained with Alcian blue solution at room temperature for 1 hour. $A$ tumor was defined as HER-2/neu positive if moderate or strong membranous staining was recorded in a significant area of the tissues.

\section{Acknowledgements}

We are grateful to all of the clinicians of Hamamatsu University Hospital, Fujieda General Hospital, and the affiliated hospitals and technical staff of the Research Equipment Center for their cooperation in this study.

\section{References}

Abarbanel J, Shabtai F, Kyzer S, and Chaimof C (1991). Cytogenetic studies in patients with gastric cancer. World J Surg 15:778-782.

David L, Seruca R, Nesland JM, Soares P, Sansonetty F, Holm R, Borresen AL, and Sobrinho-Simoes M (1992). c-erbB-2 expression in primary gastric carcinomas and their metastases. Mod Pathol 5:384-390.

Gomyo Y, Osaki M, Kaibara N, and Ito H (1996). Numerical aberration and point mutation of p53 gene in human gastric intestinal metaplasia and well-differentiated adenocarcinoma: Analysis by fluorescence in situ hybridization (FISH) and PCR-SSCP. Int J Cancer 66:594-599.

Guilford PJ, Hopkins JB, Grady WM, Markowitz SD, Willis J, Lynch H, Rajput A, Wiesner GL, Lindor NM, Burgart LJ, Toro $\pi$, Lee D, Limacher JM, Shaw DW, Findlay MP, and Reeve $A E$ (1999). E-cadherin germline mutations define an inherited cancer syndrome dominated by diffuse gastric cancer. Hum Mutat 14:249-255.

Kallioniemi A, Kallioniemi OP, Sudar D, Rutovitz D, Gray JW, Waldman F, and Pinkel D (1992). Comparative genomic hybridization for molecular cytogenetic analysis of solid tumors. Science 258:818-821.

Kim JH, Takahashi T, Chiba I, Park JG, Birrer MJ, Roh JK, De Lee H, Kim JP, Minna JD, and Gazdar AF (1991). Occurrence of p53 gene abnormalities in gastric carcinoma tumors and cell lines. J Natl Cancer Inst 83:938-943.

Kitayama $\mathrm{Y}$, Igarashi $\mathrm{H}$, and Sugimura $\mathrm{H}$ (1999). Amplification of FISH signals using intermittent microwave irradiation for analysis of chromosomal instability in gastric cancer. Mol Pathol 52:357-359.

Kitayama Y, Igarashi H, and Sugimura H (2000a). Different vulnerability among chromosomes to numerical instability in gastric carcinogenesis: Stage-dependent analysis by FISH with the use of microwave irradiation. Clin Cancer Res 6:3139-3146.

Kitayama $\mathrm{Y}$, Igarashi $\mathrm{H}$, and Sugimura H (2000b). Initial intermittent microwave irradiation for fluorescence in situ hybridization analysis in paraffin-embedded tissue sections of gastrointestinal neoplasia. Lab Invest 80:779-781.

Kobayashi K, Kitayama Y, Igarashi H, Yoshino G, Kobayashi $\mathrm{T}$, Kazui T, and Sugimura $\mathrm{H}$ (2000). Intratumor heterogeneity of centromere numerical abnormality in multiple primary gastric cancers: Application of fluorescence in situ hybridization with intermittent microwave irradiation on paraffinembedded tissue. Jpn J Cancer Res 91:1134-1141.

Kuniyasu $\mathrm{H}$, Yasui W, Kitadai $\mathrm{Y}$, Yokozaki $\mathrm{H}$, Ito $\mathrm{H}$, and Tahara $E$ (1992). Frequent amplification of the c-met gene in scirrhous type stomach cancer. Biochem Biophys Res Commun 189:227-232.

Lan HY, Mu W, Ng YY, Nikolic-Paterson DJ, and Atkins RC (1996). A simple, reliable, and sensitive method for nonradioactive in situ hybridization: Use of microwave heating to improve hybridization efficiency and preserve tissue morphology. J Histochem Cytochem 44:281-287.

Lengauer C, Kinzler KW, and Vogelstein B (1997). Genetic instability in colorectal cancers. Nature 386:623-627.

Lengauer C, Kinzler KW, and Vogelstein B (1998). Genetic instabilities in human cancers. Nature 396:643-649.

Lichter P, Boyle AL, Cremer T, and Ward DC (1991). Analysis of genes and chromosomes by nonisotopic in situ hybridization. Genet Anal Tech Appl 8:24-35.

Matozaki T, Sakamoto C, Suzuki T, Matsuda K, Uchida T, Nakano O, Wada K, Nishisaki H, Konda Y, Nagao M, et al (1992). p53 gene mutations in human gastric cancer: Wildtype $\mathrm{p} 53$ but not mutant p53 suppresses growth of human gastric cancer cells. Cancer Res 52:4335-4341.

Mori M, Tokino T, Yanagisawa A, Kanamori M, Kato Y, and Nakamura $Y$ (1992). Association between chromosome 11 q13 amplification and prognosis of patients with oesophageal carcinomas. Eur J Cancer 28A:755-757.

Nakatsuru S, Yanagisawa A, Furukawa Y, Ichii S, Kato Y, Nakamura $Y$, and Horii A (1993). Somatic mutations of the APC gene in precancerous lesion of the stomach. Hum Mol Genet 2:1463-1465. 
Nishi M, Omori Y, and Miwa Y, editors (1995). Japanese Classification of Gastric Carcinoma. Kanehara, Tokyo: Japanese Research Society for Gastric Cancer.

Ochi H, Douglass HO Jr, and Sandberg AA (1986). Cytogenetic studies in primary gastric cancer. Cancer Genet Cytogenet 22:295-307.

Pinkel D, Straume T, and Gray JW (1986). Cytogenetic analysis using quantitative, high-sensitivity, fluorescence hybridization. Proc Natl Acad Sci USA 83:2934-2938.

Ranzani GN, Renault B, Pellegata NS, Fattorini P, Magni E, Bacci F, and Amadori D (1993). Loss of heterozygosity and K-ras gene mutations in gastric cancer. Hum Genet 92:244249.

Rao PH, Mathew S, Lauwers G, Rodriguez E, Kelsen DP, and Chaganti RS (1993). Interphase cytogenetics of gastric and esophageal adenocarcinomas. Diagn Mol Pathol 2:264-268.

Renault B, van den Broek M, Fodde R, Wijnen J, Pellegata NS, Amadori D, Khan PM, and Ranzani GN (1993). Base transitions are the most frequent genetic changes at P53 in gastric cancer. Cancer Res 53:2614-2617.

Schlemper RJ, Riddell RH, Kato Y, Borchard F, Cooper HS, Dawsey SM, Dixon MF, Fenoglio-Preiser CM, Flejou JF, Geboes K, Hattori T, Hirota T, Itabashi M, Iwafuchi M, Iwashita A, Kim YI, Kirchner T, Klimpfinger M, Koike M, Lauwers GY, Lewin KJ, Oberhuber G, Offner F, Price AB, Rubio CA, Shimizu M, Shimoda T, Sipponen P, Solcia E, Stolte M, Watanabe H, and Yamabe H (2000). The Vienna classification of gastrointestinal epithelial neoplasia. Gut 47: 251-255.
Schraml P, Kononen J, Bubendorf L, Moch H, Bissig H, Nocito A, Mihatsch MJ, Kallioniemi OP, and Sauter G (1999). Tissue microarrays for gene amplification surveys in many different tumor types. Clin Cancer Res 5:1966-1975.

Seruca R, Castedo S, Correia C, Gomes P, Carneiro F, Soares P, de Jong B, and Sobrinho-Simoes M (1993). Cytogenetic findings in eleven gastric carcinomas. Cancer Genet Cytogenet 68:42-48.

Sibony M, Commo F, Callard P, and Gasc JM (1995). Enhancement of mRNA in situ hybridization signal by microwave heating. Lab Invest 73:586-591.

Simpson JF, Quan DE, Ho JP, and Slovak ML (1996). Genetic heterogeneity of primary and metastatic breast carcinoma defined by fluorescence in situ hybridization. Am J Pathol 149:751-758.

Song JP, Kitayama Y, Igarashi H, Guo RJ, Wang YJ, Kobayashi $\mathrm{T}$, Konno $\mathrm{H}$, Kataoka $\mathrm{H}$, Tanaka $\mathrm{M}$, and Sugimura $\mathrm{H}$ (2002). Centromere numerical abnormality in the papillary, papillotubular type of early gastric cancer, a further characterization of a subset of gastric cancer. Int J Oncol 21:12051211.

Tsugawa K, Fushida S, and Yonemura Y (1993). Amplification of the c-erbB-2 gene in gastric carcinoma: Correlation with survival. Oncology 50:418-425.

van Dekken H, Pizzolo JG, Kelsen DP, and Melamed MR (1990). Targeted cytogenetic analysis of gastric tumors by in situ hybridization with a set of chromosome-specific DNA probes. Cancer 66:491-497. 